\title{
IMPLEMENTASI MODEL PEMBELAJARAN KOOPERATIF TIPE STAD PADA POKOK BAHASAN STRUKTUR ATOM DI KELAS X SMA NEGERI 1 SIBABANGUN
}

\author{
Bronika Septiani Sianturi \\ Surel:bronikaseptiani@yahoo.com
}

\begin{abstract}
The purpose of this study is to determine whether STAD type cooperative learning is better than conventional learning models in improving student chemistry learning outcomes on the subject of atomic structure in class $X$ SMA 1 Sibabangun. This research is an experimental research. The population in this study was all students of class X SMA 1 Sibabangun consisting of 3 classes. The research sample was selected 2 classes randomly, namely class $X-1$ as the experimental class using cooperative learning type STAD and class X-2 as the learning control class using conventional learning. From the data analysis for the experimental class, pre-tests $(20.65 \pm 6.47)$ and post-tests $(90.8 \pm 7.35)$ were obtained. In the control class, pre-tests $(34.60 \pm 8.45)$ and post-tests were obtained (70.55 \pm 10.37). The results of testing the hypothesis by using the one-party $t$ test at $=$ 0.05 and $d k=62$ obtained tcount>ttable or 4.425>2.034 then $\mathrm{Ha}$ is accepted, Improving student learning outcomes after being given learning treatment Type STAD is better than conventional learning on the subject structure atom class X SMA Negeri 1 Sibabangun
\end{abstract}

Keywords: Implementation, Cooperative Type STAD, Learning Outcomes

\begin{abstract}
ABSTRAK
Tujuan penelitian iniuntukmengetahui apakah pembelajaran kooperatif tipe STAD lebih baik dibandingkan model pembelajaran konvensional dalam meningkatkan hasil belajar kimia siswa pada pokok bahasan struktur atom di kelas X SMA Negeri 1 Sibabangun. Penelitian ini merupakan penelitian eksperimen. Populasi dalam penelitian ini adalah seluruh siswa kelas $\mathrm{X}$ SMA Negeri 1 Sibabangun yang terdiri dari 3 kelas.Sampel penelitian ini dipilih 2 kelas secara acak yaitu kelas X-1 sebagai kelas eksperimen menggunakan pembelajaran kooperatif tipe STAD dan kelas X-2 sebagai kelas kontrol pembelajarannya menggunakan pembelajaran konvensional. Dari analisa data untuk kelas eksperimen diperoleh pre-tes $(20,65 \pm 6,47)$ danpos-tes $(90,8 \pm 7,35)$. Pada kelas kontrol diperolehpre-tes $(34,60 \pm 8,45)$ dan pos-tes $(70,55 \pm 10,37)$. Hasil pengujian hipotesis dengan menggunakan uji t satu pihak pada $\alpha=0,05$ dan dk $=62$ diperoleh $\mathrm{t}_{\text {hitung }}>\mathrm{t}_{\text {tabel }}$ atau 4,425>2,034maka Ha diterima, Peningkatan hasil belajar siswa setelah diberikan perlakuan pembelajaran Tipe STAD lebihbaik dibandingkan dengan pembelajaran konvensional pada pokok bahasan struktur atom kelas X SMA Negeri 1 Sibabangun
\end{abstract}

Kata Kunci : Implementasi, Kooperatif Tipe STAD, Hasil Belajar

\section{PENDAHULUAN}

Sebagaimana pelajaran IPA lainnya, kimia juga pelajaran yang membutuhkan pemahaman dan penalaran. Sehingga banyaksiswa yang menganggap bahwa pelajaran 
Bronika Septiani Sianturi: Implementasi Model Pembelajaran...

kimia itu sulit. Anggapan ini membawa pengaruh buruk terhadap hasil belajar kimia siswa. Banyak siswa yang tidak dapat menguasai materi-materi pelajaran kimia dengan baik sehingga hasil belajarnya rendah.

Kesulitan belajar yang dihadapi oleh siswa dan rendahnya hasil belajar kimia siswa salah satunya disebabkan oleh metode pembelajaran yang masih berpusat pada guru atau pembelajaran yang dilakukan oleh guru hanya satu arah. Oleh karena itu guru harus dituntut untuk menciptakan dan menerapkan suatu strategi dalam proses belajar mengajar agar dapat mencapai tujuan belajar siswa. Permasalahan belajar di atas juga ditemukan pada siswa yang ada di SMA Negeri 1 Sibabangun, sehingga perlu diterapkan suatu model pembelajaran kimia yang mendorong siswa aktif dalam belajar. Model pembelajaran kooperatif salah satunya adalah tipe STAD dapat dijadikan model alternatif yang diharapkan dapat mengaktifkan siswa dalam proses belajar mengajar. Dalam arti siswa harus aktif, saling berinteraksi dengan teman-temannya, saling tukar informasi, dan memecahkan masalah sehingga tidak ada siswa yang pasif dalam menyelesaikan masalah pelajaran, yang ada adalah untuk menuntaskan materi belajarnya.

Oleh karena itu untuk membantu siswa agar lebih aktif dapat digunakan pembelajaran kooperatif tipe STAD yang mengacu pada keaktifan siswa secara berkelompok maupun secara individual dalam mengemukakan serta memahami konsep-konsep pelajaran yang diajarkan. Dalam pembelajaran kooperatif tipe STAD siswa tidak hanya bertanggung jawab atas dirinya sendiri tetapi juga bertanggung jawab atas semua anggota kelompok untuk sama-sama bisa menyelesaikan soal dan memahami konsep kimia yang dipelajari.

Tipe STAD ini menciptakan suasana dimana siswa harus bekerjasama dengan teman kelompoknya untuk meningkatkan perolehan nilai kelompoknya. Karena nilai kelompok bergantung pada nilai yang diperoleh siswa secara individual. Pembelajaran tipe STAD ini diharapkan dapat melibatkan siswa secara aktif dalam proses pembelajaran dan dapat mengaktifkan, mengefisienkan, dan menarik minat belajar kimia.

Materi struktur atom merupakan materi yang diajarkan pada siswa kelas X di SMA. Struktur atom ini menjelaskan tentang susunan partikel penyusun atom, teori atom dan konfigurasi elektron. Adapun teori atom teori atom Dalton, teori atom Thomson, teori atom Rutherford, teori atom Bohr. Permasalahan yang menarik adalah bagaimana memberi konsep abstrak yang jelas kepada siswa tentang isi pokok bahasan struktur atom.

Dari uraian latar belakang masalah di atas, maka peneliti ingin melakukan penelitian yang berjudul "Implementasi Model Pembelajaran 
Kooperatif Tipe STAD Terhadap Hasil Belajar Kimia Siswa Pada Pokok Bahasan Struktur Atom Di Kelas X SMA Negeri 1 Sibabangun”.

Adapun tujuan dalam penelitian ini adalah untuk mengetahui apakah pembelajaran kooperatif tipe STAD lebih baik dibandingkan model pembelajaran konvensional dalam meningkatkan hasil belajar kimia siswa pada pokok bahasan struktur atom di kelas X SMA Negeri 1 Sibabangun.

\section{METODE PENELITIAN}

Penelitian ini dilaksanakan di SMA Negeri 1 Sibabangun Kabupaten Tapanuli Tengah padabulan September-November 2018. Dalam penelitian ini yang menjadi populasi adalah seluruh kelas $\mathrm{X}$ yang berjumlah 3 kelas di SMA Negeri 1 Sibabaungun. Sampel dalam penelitian ini ada dua kelas yaitu kelas eksperimen dan kelas kontrol. Penentuan kelas dipilih dengan menggunakan teknik pengambilan sampel secara acak. Kelas eksperimen menggunakan pembelajaran Tipe STAD dan kelas kontrol menggunakan pembelajaran Konvensional.

\begin{tabular}{lrr}
\multicolumn{1}{c}{ Dalam } & \multicolumn{2}{c}{ penelitian ini } \\
digunakan & dua & perangkat \\
pembelajaran & dan & instrumen \\
penelitian. & Perangkat & pembelajaran \\
ini yang & disusun & merupakan \\
perangkat & pembelajaran yang \\
mengarah kepada & pembelajaran \\
kooperatif tipe & STAD dan \\
pembelajaran & & konvensional.
\end{tabular}

Sedangkan instrumen penelitian umtuk memperoleh data hasil belajar siswa. 
Bronika Septiani Sianturi: Implementasi Model Pembelajaran...

Desain penelitian lebih lanjut diperlihatkan pada gambar berikut ini:

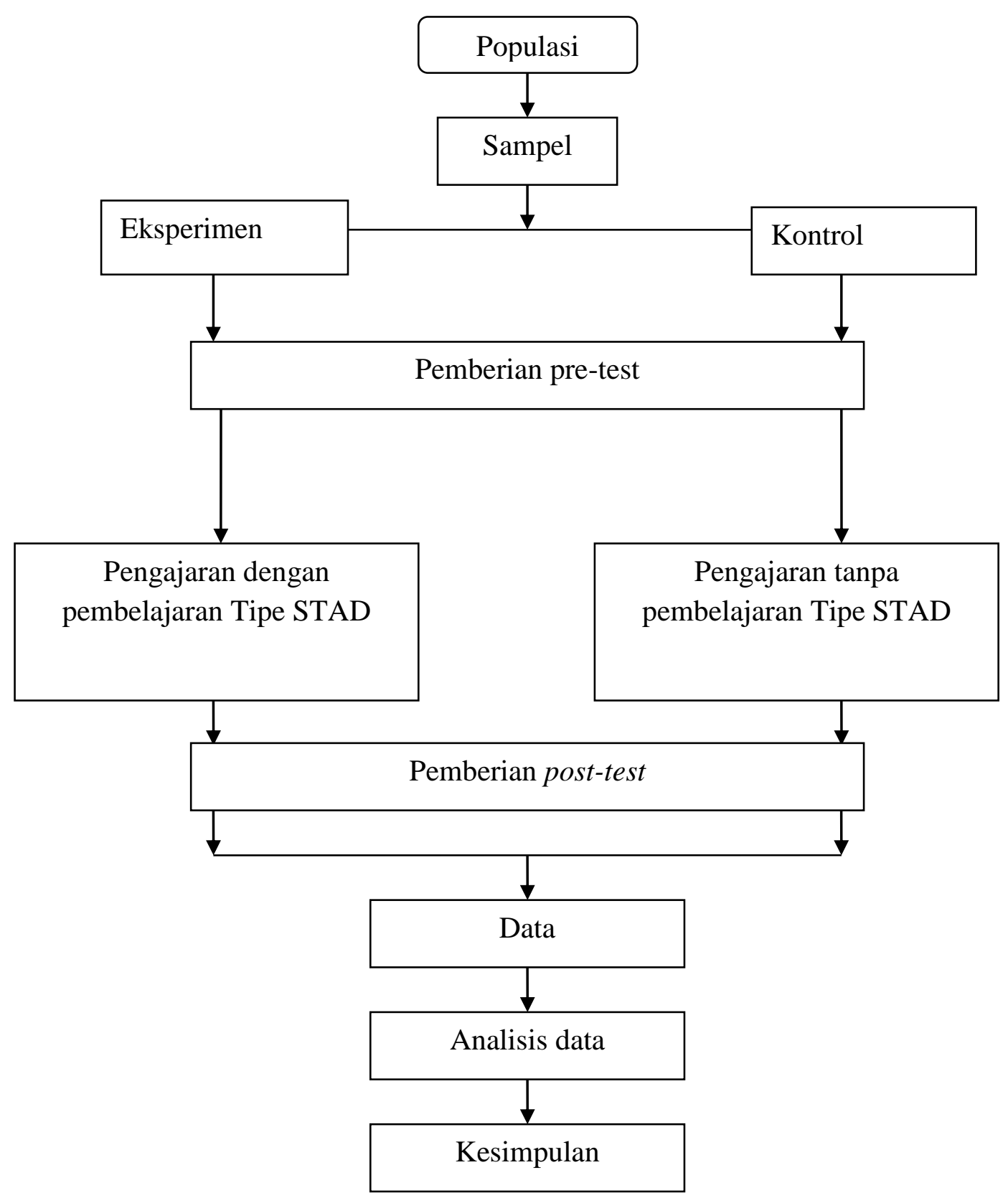

Gambar 1. Pelaksanaan Penelitian

Instrumen yang digunakan dalam penelitian ini adalah tes hasil belajar yang berbentuk tes objektif dengan empat pilihan jawaban yang terdiri dari a, b, c, dan d. Instrumen ini diujikan terlebih dahulu untuk mengetahui validitas, reliabilitas, daya pembeda tes dan tingkat kesukaran tes. Selama kegiatan belajar-mengajar peneliti bertindak sebagai pengajar. Sebelum kegiatan pembelajaran dilaksanakan siswa 
dibagi dalam beberapa kelompok, dimana dalam setiap kelompoknya terdiri dari 4-5 orang.

Menurut Meltzer keberhasilan belajar (peningkatan hasil belajar), dihitung dengan faktor gain (ternomalisasi) dengan rumus :

Gain $=$

$\frac{\text { NilaiPoste st }- \text { NilaiPr } \text { etest }}{\text { NilaiMaksimum - Nilai } \operatorname{Pr} \text { etest }}$

Uji hipotesis yang digunakan dalam penelitian ini adalah uji satu pihak (pihak kanan) sebagai berikut :

$$
\mathrm{t}_{\text {hitung }}=\frac{\overline{\mathrm{x}}_{1}-\overline{\mathrm{x}}_{2}}{\sqrt[\mathrm{s}]{\frac{1}{\mathrm{n}_{1}}}+\frac{1}{\mathrm{n}_{2}}}
$$

\section{HASIL PENELITIAN DAN PEMBAHASAN}

Berdasarkan hasil pre test pada kelas eksperimen diperoleh nilai terendah 20 dan nilai tertinggi 60 dalam konversi nilai antara 5 100 dengan nilai rata- rata 20,65 dan standar deviasi 6,47, sedangkan untuk nilai post testdiperolehnilai terendah 50 dan nilai tertinggi 90 dengan nilai rata- rata 90,8 dan standar deviasi 7,35. Untuk melihat secara keseluruhan, maka dapat dilihat pada daftar frekuensi pada tabel berikut :

Tabel 1. Nilai Pre-Test

\begin{tabular}{c|c|c|c}
\hline Kelas & Interval Nilai & F Kumulatif & Persentase \\
\hline 1 & $20-25$ & 3 & $10,5 \%$ \\
\hline 2 & $26-32$ & 4 & $13,15 \%$ \\
\hline 3 & $33-39$ & 9 & $31,57 \%$ \\
\hline 4 & $40-46$ & 5 & $15,78 \%$ \\
\hline 5 & $47-53$ & 4 & $13,15 \%$ \\
\hline 6 & $54-60$ & 5 & $15,78 \%$ \\
\hline \multicolumn{2}{|c|}{ Jumlah } & 30 & $100 \%$ \\
\hline
\end{tabular}

Tabel 2. Nilai Post- Tes

\begin{tabular}{c|c|c|c}
\hline Kelas & Interval Nilai & F Kumulatif & Persentase \\
\hline 1 & $50-56$ & 1 & $2,63 \%$ \\
\hline 2 & $57-64$ & 3 & $10,52 \%$ \\
\hline 3 & $65-72$ & 5 & $15,78 \%$ \\
\hline 4 & $73-80$ & 13 & $42,10 \%$ \\
\hline 5 & $81-88$ & 3 & $10,52 \%$ \\
\hline 6 & $89-96$ & 6 & $18,42 \%$ \\
\hline \multicolumn{2}{|c|}{ Jumlah } & 31 & $100 \%$ \\
\hline
\end{tabular}


Berdasarkan hasil pre test pada kelas control diperoleh nilai terendah 20 dan nilai tertinggi 55 dalam konversi nilai antara $5-100$ dengan nilai rata- rata 31,86 dan standar deviasi 8,45 sedangkan untuk nilai post test diperoleh nilai terendah 50 dan nilai tertinggi 70 dengan nilai rata- rata 70,55 dan standar deviasi 10,37.

Telah diketahui bahwa kedua data adalah berdistribusi normal dan mempunyai varian yang sama atau homogen dengan demikian pengujian hipotesis dilakukan melalui uji $\mathrm{t}$ atau melalui uji perbedaan dua rata- rata. Dari perhitungan diperoleh $\mathrm{t}_{\text {hitung }}=$ 4,425. Berdasarkan tabel statistik dengan $\mathrm{dk}=62$ dan $\alpha=0,05$ diperoleh $t_{\text {tabel }}=2,034$. Ternyata $t_{\text {hitung }}>\quad t_{\text {tabel }}$ yaitu 4,425>2,034 menunjukkan bahwa hasil belajar siswa yang mendapat pembelajaran kooperatif tipe STAD lebih tinggi dari hasil belajar siswa yang mendapat Pembelajaran konvensional pada pokok bahasan struktur atomdi kelas X SMA Negeri 1 Sibabangun. Dengan kata lain bahwa pembelajaran kooperatif tipe STAD lebih efektif dibandingkan dengan pembelajaran konvensional dalam meningkatkan hasil belajar siswa.

\section{Pembahasan}

Berdasarkan hasil penelitian menunjukkan bahwa peningkatan hasil belajar kimia siswa yang diajar dengan penerapan model pembelajaran kooperatif tipe STAD $(59,8 \%)$ pada pokok bahasan struktur atom lebih tinggi daripada peningkatan hasil belajar kimia siswa yang diajar dengan pembelajaran secara konvensional(45,9\%). Hal ini dapat dilihat dari nilai rata-rata pretest siswa kelas eksperimen adalah 20,65 dengan standar deviasi 6,47. Sedangkan nilai rata-rata pos-test siswa kelas eksperimen adalah 90,8 dengan standar deviasi 7,35. Ketuntasan belajar siswa pada kelas eksperimen mencapai $80,21 \%$ (melebihi syarat ketuntasan minimal, yaitu $75 \%$ ).

Sedangkan pada kelas kontrol diperoleh nilai rata-rata pre-test siswa sebesar 34,60 dengan standar deviasi 8,45 dan nilai rata-rata posttest siswa kelas kontrol adalah 70,55 dengan standar deviasi 8,45. Ketuntasan belajar siswa pada kelas kontrol mencapai 63,21\% (tidak memenuhi syarat ketuntasan minimal, yaitu 75\%).

Selain itu, kita juga dapat melihat dari hasil perhitungan nilai rata- rata dan pengujian hipotesis. Dari pengujuian hipotesis diperoleh bahwa $\mathrm{t}$ hitung 4,425dan $\mathrm{t}$ tabel $=$ 2,034 (t hitung $>\mathrm{t}$ tabel) pada $\alpha=$ 0,05 yang menunjukkan bahwa $\mathrm{H}_{\mathrm{o}}$ ditolak dan $\mathrm{H}_{\mathrm{a}}$ diterima. Hal ini menunjukkan bahwa hasil belajar siswa yang mendapat pembelajaran kooperatif tipe STAD lebih tinggi dari hasil belajar siswa yang mendapat Pembelajaran konvensional pada pokok bahasan struktur atom di kelas X SMA Negeri 1 Sibabangun. Pembelajaran dengan pembelajaran kooperatif tipe STAD khususnya dalam memberikan 
contoh teori Atom membuat siswa aktif dan lebih termotivasi dalam belajar. Dengan penggunaan pembelajaran kooperatif tipe STAD ini, mereka lebih mudah untuk memahami teori-teori atom.

Berbeda

pembelajaran

konven

meskipun guru dapat dengan mudah menguasai kelas dan dapat merangkum atau menjelaskan pokokpokok materi yang penting dalam waktu singkat, akan tetapi siswa pasif akibatnya siswa hanya akan mendengar dan bertumpu pada apa yang diucapkan oleh guru dan ada juga siswa yang tidak mendengar dan menyimak penjelasan guru dengan baik akibatnya motivasi belajar siswa akan berkurang. Apabila diberi contoh atau permasalahan baru maka siswa akan bingung dan seolah-olah sulit mengembangkan teori dengan contoh yang diberikan. Akibatnya hasil belajar yang diperoleh lebih rendah dibandingkan dengan hasil belajar siswa yang diajarkan dengan menggunakan model pembelajaran kooperatif tipe STAD.

Hasil penelitian yang diperoleh tentang mengapa model pembelajaran kooperatif tipe STAD memberikan hasil yang lebih baik adalah:

a. Dengan model pembelajaran kooperatif tipe STAD yang dilakukan membuat siswa dapat mengembangkan kemampuan berpikirnya yang dimulai dengan mengajukan pertanyaan dan direspon oleh siswa lain yang mendengar. b. Dengan model pembelajaran kooperatif tipe STAD maka siswa akan lebih aktif dalam mengikuti pelajaran.

c. Model pembelajaran kooperatif tipe STAD merangsang keingintahuan siswa untuk menemukan sendiri contohcontoh materi pembelajaran yang terdapat dalam buku dan dalam kehidupan sehari- hari.

d. Rasa bosan dan minat belajar yang rendah lenyap setelah diberi pelajaran dengan model pembelajaran kooperatif tipe STAD.

\section{SIMPULAN}

a. Hasil belajar siswa yang diajarkan dengan model pembelajaran kooperatif tipe STAD lebih tinggi dibandingkan dengan hasil belajar siswa yang diajarkan dengan pembelajaran konvensional sebesar 59,8\%

b. Rasa bosan siswa berkurang setelah diberi pengajaran dengan model pembelajaran kooperatif tipe STAD dan terjadi peningkatan minat dan keingintahuan siswa tentang pelajaran yang diajarkan.

c. Dengan pembelajaran kooperatif tipe STAD maka siswa akan berlatih dalam kelompok yang dibentuk.

d. Dengan pembelajaran kooperatif tipe STAD maka siswa akan berlatih untuk dapat bekerjasama dalam kelompoknya. 
Bronika Septiani Sianturi: Implementasi Model Pembelajaran...

\section{DAFTAR RUJUKAN}

Arikunto, S. 2002. Prosedur

Penelitian Suatu Pendekatan

Praktik. Jakarta: PT. Rineka Cipta.

Hamalik. 2008. Proses Belajar Mengajar. Jakarta: PT. Bumi Aksara.

Ibrahim. 2000. Pembelajaran Kooperatif. Surabaya: Universitas Surabaya.

Lie, Anita. 2008. Cooperative Learning. Jakarta: Penerbit Grasindo.

Sardiman. 2008. Interaksi dan Motivasi Belajar Mengajar. Jakarta: Raja Grafindo Persada. Slameto. 2003. Belajar dan FaktorfaktorYang Mempengaruhiny. Jakarta: Rineka Cipta. 